\title{
Adapting the WHO tool on sexual and reproductive health and human rights: Experiences in four countries
}

\author{
lan Askew \\ Population Council \\ Kaila Clarke \\ Population Council \\ Fauzia Akhter Huda \\ Joyce Mumah \\ Mary Philip Sebastian \\ Population Council
}

Follow this and additional works at: https://knowledgecommons.popcouncil.org/departments_sbsr-rh

Part of the International Public Health Commons, Social and Behavioral Sciences Commons, and the Women's Health Commons

How does access to this work benefit you? Let us know!

\section{Recommended Citation}

Askew, lan, Kaila Clarke, Fauzia Akhter Huda, Joyce Mumah, and Mary Philip Sebastian. 2013. "Adapting the WHO tool on sexual and reproductive health and human rights: Experiences in four countries," presentation at the International Conference on Family Planning, Addis Ababa, Ethiopia. 


\section{Adapting the WHO Tool on Sexual and Reproductive Health and Human Rights: Experiences in Four Countries}

lan Askew (Population Council)

Kaila Clarke (Population Council, Senegal)

Fauzia Akhter Huda (icddr,b, Bangladesh)

Joyce Mumah (African Population and Health Research Center, Kenya) Mary Sebastian (Population Council, India)

International Conference on Family Planning

Addis Ababa, Ethiopia

November 12 - 152013 


\section{Why the WHO SRH\&HR tool?}

- Provides a human rights framework to identify legal, policy and regulatory barriers

- Restricting accessibility and availability

- Inhibiting acceptability and quality

- Helps countries recognise and address three rights principles:

$>$ Non-discrimination

$>$ Participation

$>$ Accountability

- Enables countries to relate their laws, policies and practices to international human rights treaties

WHO's Department of Reproductive Health and Research and the Harvard School of Public Health's Program on International Health and Human Rights
Sexual and reproductive health
and human rights

6) Worth heath

A tool for examining laws,
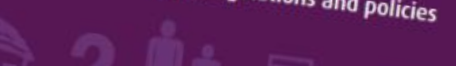


\section{The SRH\&HR tool: original and adapted}

\section{$\underline{\text { Original }}$}

- Phase 1: Initiating the Process

- Establishing commitment and leadership

- Establishing the national project team

- Contracting the researchers and project coordinator

- Introductory workshop

- Phase 2: Data compilation

- Adaptation of the instrument

- Data compilation

- Analysis workshop and analysis

- Phase 3: Planning for action and implementation

- Stakeholder workshop

- Final report and dissemination

- Monitoring, evaluation and follow-up

\section{Adapted for STEP UP} Country Profiles
- Phase 1: Design Country Profile

- Stakeholder meetings to identify evidence gaps for unintended pregnancy in each country

- Create data checklist instrument, including section on SRH\&HR

- Phase 2: Data compilation

- Desk review of existing documents

- Interviews with key informants

- Draft report prepared

- Phase 3: Planning for action and implementation

- Stakeholder validation meeting held

- Final report and dissemination

- Follow-up 


\section{The original, validated instrument}

- Part 1: Human rights and the legal context

1. International and regional commitments

2. Mechanisms for promoting and protecting human rights

3. Population and demographic laws, policies and goals

4. Status of women

- Part 2: Cross-cutting human rights principles

1. Non-discrimination and equality

2. Accessibility of sexual and reproductive health services

3. Access to information

4. Informed consent

5. Respecting the best interests, evolving capacities and view of the child

6. Privacy and confidentiality

7. Education

8. Use of available resources

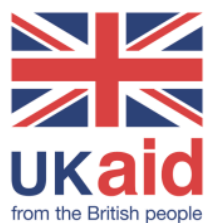

- Part 3:Core health issues

1. Pregnancy and childbirth

2. Family planning

3. Abortion

4. Sexually transmitted infections, including HIV and reproductive morbidities

5. Sexual health

\section{Policy \& practice}

Using human rights for sexual and reproductive health:

improving legal and regulatory frameworks

Jane Cottingham, ${ }^{a}$ Eszter Kismodi, ${ }^{b}$ Adriane Martin Hilber, ${ }^{c}$ Ornella Lincetto, ${ }^{d}$ Marcus Stahlhofere \& Sofia Gruskin ${ }^{\dagger}$

Abstract This paper describes the development of a tool that uses human rights concepts and methods to improve relevant laws, regulations and policies related to sexual and reproductive health. This tool aims to improve awareness and understanding of States' human rights obligations. It includes a method for systematically examining the status of vulnerable groups, involving non-health sectors, fostering a genuine process of civil society participation and developing recommendations to address regulatory and policy barriers to sexual and reproductive health with a clear assignment of responsibility. Strong leadership from the ministry of health, with support from the World Health Organization or other international partners, and the serious engagement of all involved in this process can strengthen the links between human rights and sexual and reproductive health, and contribute to national achievement of the highest attainable standard of health.

Buw World Hasith Organ 2010;88:551-555 I doi:10.2471/BLT.09.063412

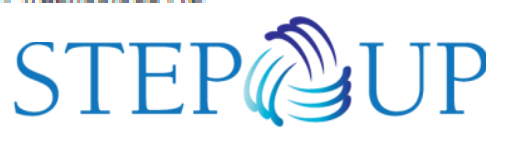




\section{Adapting the instrument to the Country Profile}

- 'Human rights and legal context' issues included

- "Mechanisms" often integrated into descriptions of commitments, laws, policies and goals

- Clarifies linkages with international treaties

- "Status of women" rarely documented

- 'Cross-cutting human rights principles' proved difficult to incorporate

- "Non-discrimination and equality" most fully reported, through descriptions of various population groups

- "Education" well-represented throughout reports

- Limited descriptions of other principles

- 'Core health issues' well described overall

- STIs, reproductive morbidities and sexual health poorly reported probably because of indirect link with unintended pregnancy 


\section{Experiences with using the adapted instrument}

$\checkmark$ Provided a checklist against which study coordinators could ensure inclusion of a full range of rights issues

$\checkmark$ Less participatory process followed

$\checkmark$ Descriptions easier than interpretations:

- Insufficient orientation before study initiation

- Broader focus on unintended pregnancy diluted analysis and presentation of rights perspective

$\checkmark$ Stimulated stakeholder discussions of many issues, especially:

- Interpretation of laws, policies and programmes from rights perspective

- Abortion and adolescents clearly most challenging issues

- Overall, laws and policies for FP appear to be rights-based, but understanding, interpretation and implementation problematic 


\section{In summary...}

1. Provides a birds-eye view of human rights obligations and the potential for their full enjoyment through a review of national laws, policies and programmes

2. Process tool vs. data compilation instrument

- Who participates

- Use of findings

- Recommendations

- Actions

- Accountability role

3. Highlights sensitive issues and stimulates discussion

4. Challenge of stimulating action from recommendations

5. More to follow... 

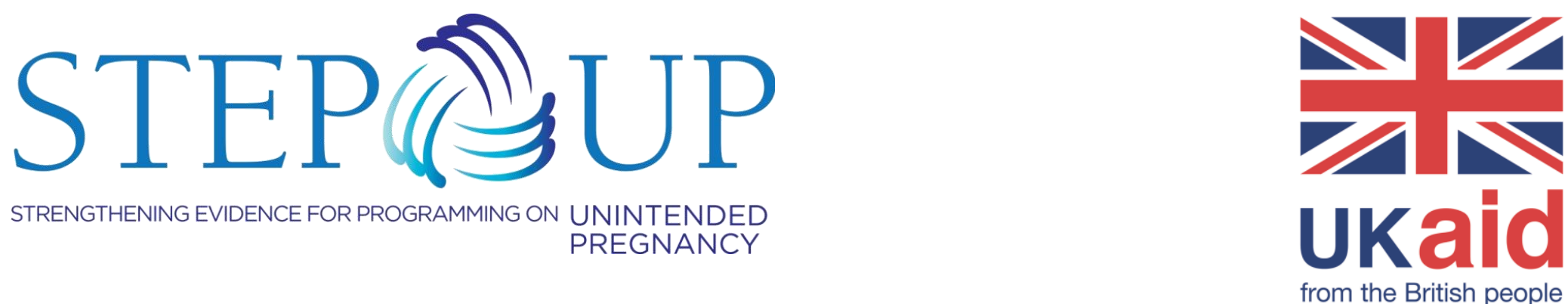

STRENGTHENING EVIDENCE FOR PROGRAMMING ON UNINTENDED

The STEP UP (Strengthening Evidence for Programming on Unintended Pregnancy) Research Programme Consortium is coordinated by the Population Council in partnership with the African Population and Health Research Center; icddr,b; the London School of Hygiene and Tropical Medicine; Marie Stopes International; and Partners in Population and Development. STEP UP is funded by UK aid from the UK Government.

\section{(2) Population Council}

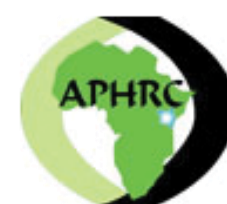
African Population and Health Research Center
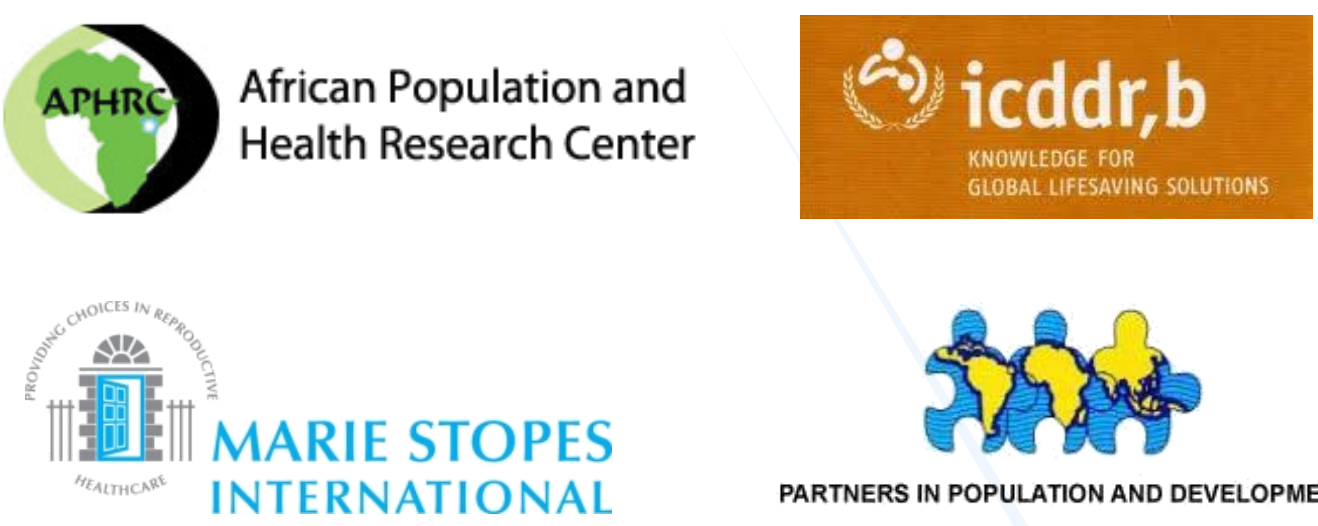

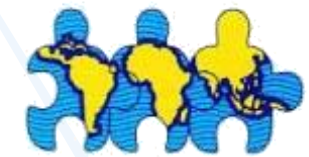

PARTNERS IN POPULATION AND DEVELOOPMENT
LONDON SCHOOL of HYGIENE MEDICINE

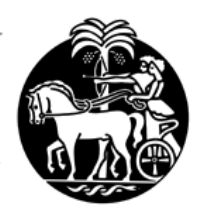

